Article

\title{
Functionalized Electrospun Poly(Vinyl Alcohol) Nanofibrous Membranes with Poly(Methyl Vinyl Ether-Alt-Maleic Anhydride) for Protein Adsorption
}

\author{
Mesbah Najafi *, Joronia Chery and Margaret M. Frey \\ Department of Fiber Science \& Apparel Design, Cornell University, Ithaca, NY 14853, USA; \\ jc2566@cornell.edu (J.C.); mfw24@cornell.edu (M.M.F.) \\ * Correspondence: mn574@cornell.edu; Tel.: +1-(607)-255-3151
}

Received: 12 May 2018; Accepted: 11 June 2018; Published: 13 June 2018

\begin{abstract}
In this work, electrospun poly(vinyl alcohol) (PVA) nanofiber membranes were functionalized by incorporating poly(methyl vinyl ether-alt-maleic anhydride) (poly(MVE/MA), PMA) for the selective adsorption of proteins. The capture performance was regulated by an optimizing buffer $\mathrm{pH}, \mathrm{PMA}$ content, and protein concentration. Lysozyme was used as the model protein and a high adsorption capacity of $476.53 \pm 19.48$ was obtained at $\mathrm{pH} 6$, owing to the electrostatic attraction between the negatively charged nanofibers and positively charged proteins. The large specific surface area, highly open porous structure, and abundant available carboxyl groups contributed to such high adsorption performance. Moreover, the nanofiber membranes exhibited good reusability and good selectivity for positively charged proteins. The obtained results can provide a promising method for the purification of proteins in small analytic devices.
\end{abstract}

Keywords: electrospinning; protein; adsorption; separation; polymer; nanofiber

\section{Introduction}

The purification and separation of proteins has become an essential prerequisite in present life science research, the pharmaceutical field, and the biomedical industry. Purified proteins are required for many experimental applications, such as structural studies, in vitro biochemical assays, biosensors and other protein-based analytical devices [1,2]. Several purification methods such as centrifugation, ultrafiltration, dialysis, sedimentation, adsorption, and chromatography have been developed. Among them, adsorption is of particular interest because of its cost-efficiency, time-efficiency, and ease in processing [3]. Traditionally, porous resin beads and gel microspheres have been used to capture selected species from protein mixtures [4]. The inherent problems of high pressure drops, high solution consumption, limited binding capacity, and low processing rates have restricted their use in large-scale applications $[3,5]$.

Electrospun nanofiber membranes (ENMs) are excellent candidates for the adsorption of proteins because of their high specific surface area (SSA), highly tortuous porous structure, and robust mechanical properties [6]. In particular, these nanofibers facilitate chemical/biological functionalization, as the majority of the binding sites on their surface are external and accessible, which leads to a superb adsorption capacity. Several studies have been carried out to functionalize ENM surfaces for protein capture [7-11]. Ma et al. [7] functionalized electrospun poly(ether sulfone) (PSU) membranes with protein $A / G$, and the obtained nanofibers specifically adsorbed protein IgG with a binding capacity of $11.42 \mathrm{mg} / \mathrm{g}$. Chiu et al. [9] hydrolyzed polyacrylonitrile nanofibrous membranes with sodium hydroxide and the obtained materials absorbed lysozyme with a capture capacity of $83.2 \mathrm{mg} / \mathrm{g}$. Zhang et al. [10] covalently reacted a dye, Cibacron Blue F3GA, to the electrospun hybrid 
chitosan/nylon-6 nanofibrous membrane and the resultant adsorbents captured papain with a capacity of about $70 \mathrm{mg} / \mathrm{g}$. Also, Schneiderman et al. [11] treated carbon nanofibers with nitric acid at $90{ }^{\circ} \mathrm{C}$ for $48 \mathrm{~h}$ to introduce carboxylate groups into a nanofiber surface for protein adsorption. The adsorption capacity of the nanofiber mats was about 10 times higher than that of the microfiber counterparts. Although these studies improved the adsorption performance of the nanofibers, the complexity of the chemical reactions, low adsorption efficiency, low binding protein capacity, and high cost of affinity ligands make them inappropriate for production in a large scale.

In this study, we examined the effectiveness of functionalized electrospun PVA nanofiber membranes for protein adsorption. Our research group earlier demonstrated that PVA nanofibers can be functionalized by incorporating functional polymer poly(hexadimethrine bromide) (PB) with amine groups or poly(methyl vinyl ether-alt-maleic anhydride) (PMA) with carboxyl groups to create positively- and negatively-charged surfaces, respectively [12-16]. The surface charges of these nanofibers were confirmed previously by the thermally stimulated current (TSC) method [12]. Colangelo et al. utilized these nanofibers as on-chip biosensors for the immobilization of liposome and E. coli cells within microfluidic channels [13,14]. Also, Xiao et al. [12] recently used these charged nanofibers to selectively capture cationic dye methylene blue (MB) and acid red 1 (AR1) anionic dye from a dye mixture.

Herein, we investigated the protein adsorption performance of PVA/PMA nanofiber membranes. This is the first time that such nanofibers were used for a protein study. Lysozyme (LYZ) was used as the model protein, as it has been widely used in industrial applications, such as food additives, antibacterial and anticancer agents [2]. The influence of various parameters, including $\mathrm{pH}$, PMA content, and protein concentration, on the lysozyme capture were examined. Also, the selective adsorption of the membrane was examined in a LYZ/BSA binary solute system. The large SSA, highly tortuous open-porous structure, and abundant carboxyl groups of PVA/PMA nanofibers provided an excellent adsorption capacity, short equilibrium time, favorable reusability, and selectivity. The obtained results offer new insight into the development of functionalized nanofibers for protein adsorption and purification.

\section{Materials and Methods}

A highly hydrolyzed (98\%) PVA with a molecular weight of 78,000 g/mol was purchased from Polysciences, Inc (Warrington, PA, USA). Poly(methyl vinyl ether-alt-maleic anhydride) (PMA, average $M_{\mathrm{W}}=216,000 \mathrm{~g} / \mathrm{mol}$ ), Triton X-100 (p-tertiary-octylphenoxy polyethyl alcohol) were provided by Sigma-Aldrich (St. Louise, MO, USA). Lyophilized Lysozyme (LYZ) chicken egg white and bovine serum albumin (BSA) were purchased from Millipore Sigma (Burlington, NJ, USA).

\subsection{Electrospinning}

A total of $10 \mathrm{wt} \%$ PVA was dissolved in $15 \mathrm{~mL}$ of DI-water in an oven at $95{ }^{\circ} \mathrm{C}$ for $4 \mathrm{~h}$. PMA was dissolved in $10 \mathrm{~mL}$ of DI-water in an oven at $95{ }^{\circ} \mathrm{C}$ for $1.5 \mathrm{~h}$ and then mixed with PVA aqueous solution. The mass ratios of PVA/PMA were 90/10, 80/20, and 70/30 (w/w). Nonionic surfactant Triton X-100 was added to the spinning dope to reduce the surface tension of the water $(\mathrm{X}-100 / \mathrm{DI}$-water $=0.5 / 99.5 \mathrm{w} / \mathrm{w})$. The dope was loaded into a $5 \mathrm{~mL}$ BD plastic syringe equipped with a 21 gauge stainless needle. A high voltage of $18 \mathrm{kV}$ was applied to the needle tip and a grounded aluminum collector was placed $20 \mathrm{~cm}$ away. The solution feed rate was maintained at $0.5 \mathrm{~mL} / \mathrm{h}$ using a PHS ultrasyringe pump.

\subsection{Heat Treatment}

The as-spun nanofibers were thermally treated at $120^{\circ} \mathrm{C}$ for $30 \mathrm{~min}$ under vacuum to increase the water stability of the membranes. 


\subsection{Adsorption Experiment}

Protein solutions were prepared by dissolving a certain amount of lysozyme powder in a $0.01 \mathrm{M}$ PBS buffer solution with various $\mathrm{pH}$ values. To investigate static adsorption, about $50 \mathrm{mg}$ of PVA/PMA nanofiber membranes were immersed in a $30 \mathrm{~mL}$ lysozyme solution at different concentrations $(0.2-1.0 \mathrm{mg} / \mathrm{mL})$ and the mixture was shaken at $8{ }^{\circ} \mathrm{C}$ for a certain time. The protein concentration was measured on a PerkinElmer Lambda 35 UV-VIS spectrometer (Waltham, MA, USA) before and after the addition of nanofiber membranes. The adsorption capacities of the membranes were calculated using the following equation:

$$
\mathrm{Q}_{\mathrm{e}}=\mathrm{V}\left(\mathrm{C}_{0}-\mathrm{C}_{\mathrm{e}}\right) / \mathrm{m}
$$

where $\mathrm{Q}_{\mathrm{e}}$ is the adsorption amount $(\mathrm{mg} / \mathrm{g}), \mathrm{V}$ is the volume of the protein solution $(\mathrm{mL}), \mathrm{C}_{0}$ and $\mathrm{C}_{\mathrm{e}}$ are the initial and effluent concentrations of the protein solution $(\mathrm{mg} / \mathrm{mL})$, and $\mathrm{m}$ is the amount of adsorbent (g).

To test the dynamic adsorption, several layers of the PVA/PMA membranes were sandwiched into a plastic filter holder with a diameter of $1.3 \mathrm{~mm}$. The filter holder was inserted into a $5 \mathrm{~mL}$ gastight Hamilton syringe (Reno, NV, USA) containing protein solution. The solution feed rate was maintained at $0.05 \mathrm{~mL} / \mathrm{min}$ using a PHS ultrasyringe pump (Harvard Apparatus, Holliston, MA, USA). The effluent lysozyme solution was collected $1.5 \mathrm{~mL}$ at a time and the protein concentration of each effluent was obtained via the UV-VIS spectra.

To examine the membrane reusability, the adsorbed membrane was first eluted with $4.5 \mathrm{~mL}$ sodium hydroxide $(1 \mathrm{M})$ using the syringe pump. Then, the nanofibers were rinsed by circulating $10 \mathrm{~mL}$ of DI water through the membrane to attain neutral conditions, and the adsorption experiment was repeated. To examine the protein removal, effluents were gathered during the base elution and the protein concentration of each effluent was obtained via the UV-VIS spectra.

\subsection{Membrane Characterization}

\subsubsection{FTIR Spectroscopy}

All the membrane samples were analyzed by FTIR spectrometer (PerkinElmer-Frontier, Waltham, MA, USA) in the absorbance mode, at the range $4000-600 \mathrm{~cm}^{-1}$, with a scan resolution of $4 \mathrm{~cm}^{-1}$ and an average of 15 scans.

\subsubsection{FESEM Imaging}

The morphology of the nanofibers was examined using a Zeiss 1550 Field Emission Scanning Electron Microscopy (Zeiss FESEM, Oberkochen, Germany). All samples were coated by a layer of $\mathrm{Au} / \mathrm{Pd}$ and the images were obtained at an accelerating voltage of $3.0-5.0 \mathrm{kV}$.

\section{Statistical Analysis}

The diameter of the nanofibers was measured using the ImageJ software (1.52b National Institute of Health, Bethesda, MD, USA). An average of 50 individual fiber diameter measurements were reported for each sample.

\subsubsection{BET Surface Area}

The Brunauer-Emmet-Teller (BET) surface area was characterized by measurement of the $\mathrm{N}_{2}$ adsorption-desorption isotherms at $77^{\circ} \mathrm{K}$ with a surface area analyzer (Gemini VII 2390, Micromeritics Co., Norcross, GA, USA).

\subsection{Adsorption Selectivity}

The capture selectivity of the membrane was examined using a dynamic adsorption test. To achieve this, $4 \mathrm{mg}$ of LYZ and BSA were separately dissolved in $0.01 \mathrm{M}$ PBS buffer solution with a pH 
value of 6 . Then, $2 \mathrm{~mL}$ of these solutions was mixed together to create a $0.2 \mathrm{mg} / \mathrm{mL} \mathrm{BSA} / \mathrm{LYZ}$ solution $(50 / 50 w / w)$. A dynamic adsorption test (details above) was conducted on the solution mixture and the protein effluent was gathered $1.5 \mathrm{~mL}$ at a time. LYZ solutions with various concentrations $(0.1,0.2$, $0.3,0.4 \mathrm{mg} / \mathrm{mL}$ ) were also run with the protein mixture to examine the adsorption performance. The selectivity capacity was analyzed by sodium dodecyl sulfate polyacrylamide gel electrophoresis (SDS-PAGE) (12\% gradient gel from Bio-Rad (Hercules, CA, USA) with standard Coomassie blue staining) before and after adsorption.

\section{Results and Discussion}

\subsection{Nanofiber Morphology and Structure}

Figure 1 shows the morphology of heat-treated PVA/PMA nanofiber membranes at different PMA contents. As can be seen, the nanofibers are bead-free and have a uniform shape. The diameters of the nanofibers are compared in Figure 2. As can be seen, the fiber diameter increased from $89.14 \pm 41.12$ to $177 \pm 40.51 \mathrm{~nm}$, when the PMA content increased from 10 to $30 \%$. It is known that a higher $M_{\mathrm{w}}$ polymer increases the viscosity of the electrospinning solution and results in a larger fiber diameter [17]. As the PMA has a considerably higher $M_{\mathrm{W}}$ than the PVA, the higher PMA contents can increase the solution viscosity and fiber diameter.

The BET surface area of PVA/PMA (80/20) nanofibers was $13.056 \pm 0.197 \mathrm{~m}^{2} / \mathrm{g}$, which is significantly high for materials adsorption [4]. As a high protein adsorption capacity was obtained for the $80 / 20$ blend (details in effect of PMA content), this measurement was performed on that sample. The pore size distribution of the fiber webs was measured with a capillary flow porometer. The mean flow pore diameter of the nanofiber membranes was $221.2 \pm 136.5 \mathrm{~nm}$ and the maximum pore size was $384.5 \mathrm{~nm}$. Such a high surface area and highly open porous structure provide the possibility for the nanofibers to adsorb proteins.
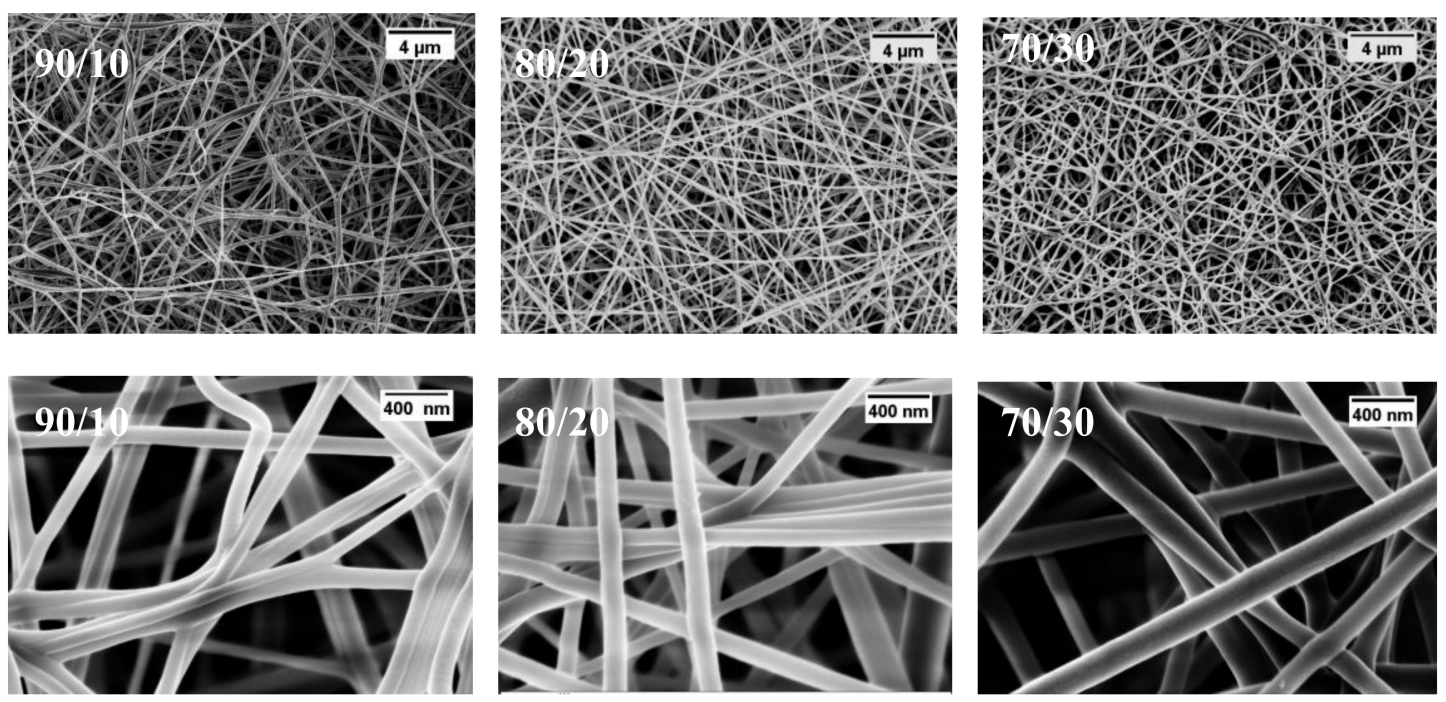

Figure 1. Fiber morphology of thermally-treated electrospun PVA/PMA membranes for different PMA contents. The morphology of pure PVA nanofibers can be found in our former study [15]. 


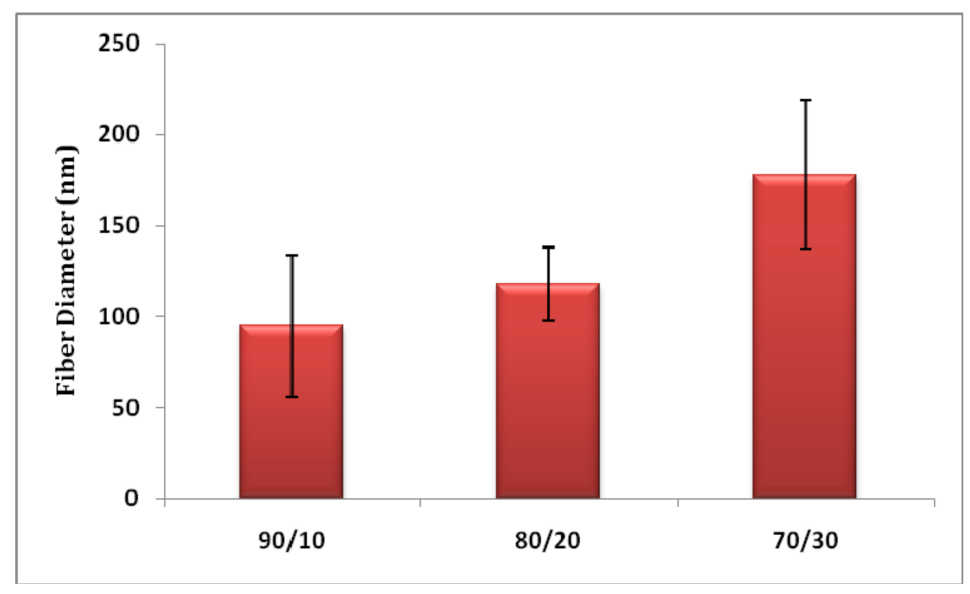

Figure 2. Nanofiber diameter of various PVA/PMA membranes after thermal treatment.

\subsection{Adsorption Performance}

Figure 3 and Table 1 display the adsorption performance of PVA/PMA membranes at different lysozyme concentrations. As we obtained a higher adsorption capacity for the PVA/PMA (80/20) ratio (details in effect of PMA content), we used this nanofiber to examine the adsorption performance. The adsorption amount first increased rapidly with the time and then reached equilibrium within about 6 to $10 \mathrm{~h}$, depending on the protein concentration. This is because initially there were many available adsorption sites on the nanofiber surface for lysozyme capture, resulting in the rapid migration of proteins from the solution on the fiber surface. Once the membrane and the protein have been in contact long enough, equilibrium will be established between the amount of proteins adsorbed on the fibers and the amount of proteins in the solution and the adsorption capacity reaches a plateau. The high adsorption capacity was $476.53 \pm 19.48 \mathrm{mg} / \mathrm{g}$, which was related to the $1.0 \mathrm{mg} / \mathrm{mL}$ lysozyme concentration. It is interesting that such a high adsorption capacity was obtained simply through the incorporation of a functionalized polymer into PVA nanofibers. Wang et al. [4] produced carboxyl-surface-functionalized nanofibers by combining electrospinning and the in-situ graft polymerization of PVA and maleic anhydride (MAH). They reported a lysozyme adsorption capacity of about $200 \mathrm{mg} / \mathrm{g}$ for the nanofibers with a $320 \mathrm{~nm}$ diameter and $3.2 \mathrm{~g} / \mathrm{m}^{2}$ BET surface area. In comparison, in our study, we initially incorporated a high $M_{\mathrm{W}}(216 \mathrm{KD}) \mathrm{PMA}$ polymer into the electrospun PVA nanofibers and our capture capacity was nearly two times that of the previously reported data. This higher capacity can be ascribed to the abundant adsorbent carboxyl groups (more details in the FTIR analysis), $270 \%$ smaller fiber diameter, and $400 \%$ higher specific surface area of the membranes. 


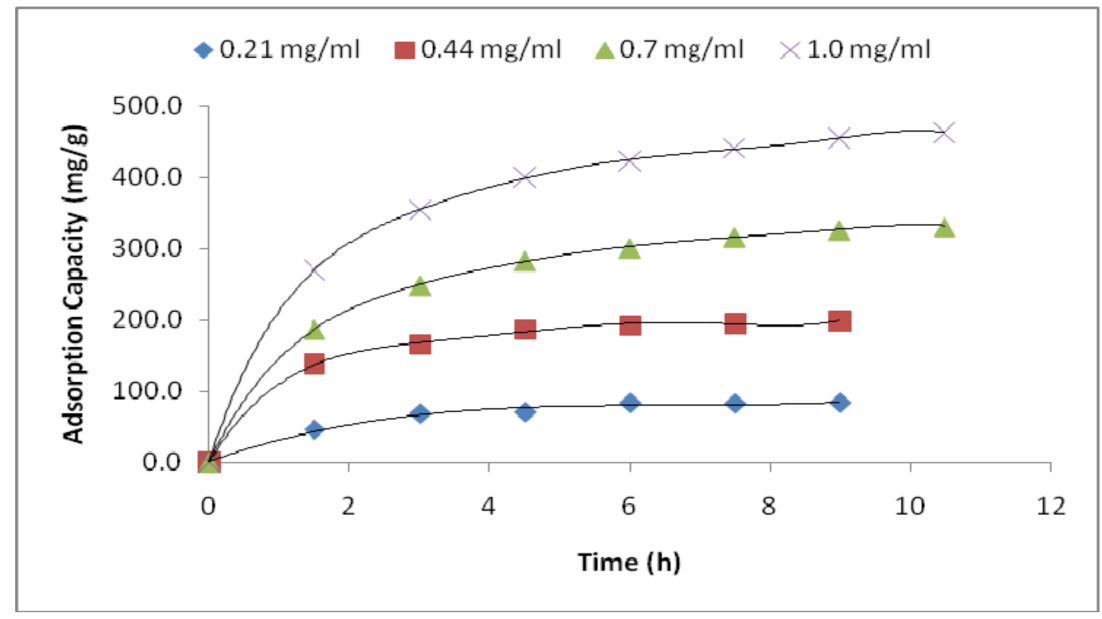

Figure 3. Static adsorption performance of the PVA/PMA $(80 / 20)$ nanofiber membrane at different lysozyme concentrations $(\mathrm{pH}=6)$ as a function of time.

Table 1. Static adsorption capacities $\left(Q_{e}\right)$ of PVA/PMA (80/20) membranes at different lysozyme concentrations.

\begin{tabular}{ccccc}
\hline LYZ Conc. $(\mathbf{m g} / \mathbf{m L})$ & $\mathbf{0 . 2 1}$ & $\mathbf{0 . 4 4}$ & $\mathbf{0 . 7}$ & $\mathbf{1 . 0}$ \\
\hline Qe $(\mathbf{m g} / \mathbf{g})$ & $86.29 \pm 3.89$ & $207.88 \pm 13.12$ & $326 \pm 7.35$ & $476.53 \pm 19.48$ \\
\hline
\end{tabular}

\subsection{Optimization of Adsorption Conditions}

\subsubsection{Effect of $\mathrm{pH}$}

The buffer $\mathrm{pH}$ plays a considerable role in protein adsorption, as it can regulate the surface charge of both nanofibers and proteins. Figure 4 displays the adsorption capacity of PVA/PMA nanofiber membranes at different $\mathrm{pH}$ values. A low protein concentration $(0.2 \mathrm{mg} / \mathrm{mL})$ was chosen for this experiment to analyze the results faster. As can be seen, at pH 12 the membrane did not adsorb lysozyme. However, when the $\mathrm{pH}$ is less than the lysozyme isoelectric point (LYZ IP), the adsorption capacity increased and reached to the maximum at $\mathrm{pH}$ 6. This phenomenon can be explained by the surface charge of nanofibers and proteins. As the LYZ IP is about 10.8, the positive charges of the protein will increase when decreasing the $\mathrm{pH}$ from 10 to 6. Moreover, PMA has functional groups maleic anhydride, which is hydrolyzed into carboxyl groups once in contact with water (Figure 5). These carboxyl groups ionized into COO- at $\mathrm{pH}>4(\mathrm{pKa}(-\mathrm{COOH}) \sim 4$ [18]) which results in negative surface charges on the nanofibers. The electrostatic attraction between the positively-charged proteins and the negatively-charged nanofibers resulted in the higher adsorption capacity at a lower $\mathrm{pH}$.

Figure 6 shows the FTIR spectra of the PVA/PMA (80/20) membranes before and after lysozyme adsorption. The spectrum of the lysozyme powder is also displayed for comparison. The amide peaks I and II at about 1643 and $1515 \mathrm{~cm}^{-1}$ related to LYZ [19] can be clearly seen at PVA/PMA + LYZ. This confirms that the protein was adsorbed on the surface of the nanofiber membranes. Moreover, the adsorption peak at $1722 \mathrm{~cm}^{-1}$ related to the carbonyl group of PMA was not present on the spectrum of the adsorbed (wet) membranes. Also, the peaks at 1091 and $3331 \mathrm{~cm}^{-1}$ related to the $\mathrm{C}-\mathrm{O}$ and O-H groups of PVA had a lower and a higher intensity compared to those of the pristine membrane. This might be related to the water inside the membrane, which can affect the FTIR peak resolution. The water can form hydrogen bonding with the hydroxyl and amide functional groups of the polymers influencing the shape/adsorption of the peaks. When the membrane was dried completely, those adsorption peaks reappeared on the spectrum. The obtained $\mathrm{pH} / \mathrm{FTIR}$ results for $0.2 \mathrm{mg} / \mathrm{mL}$ can be applied to higher lysozyme concentrations. 


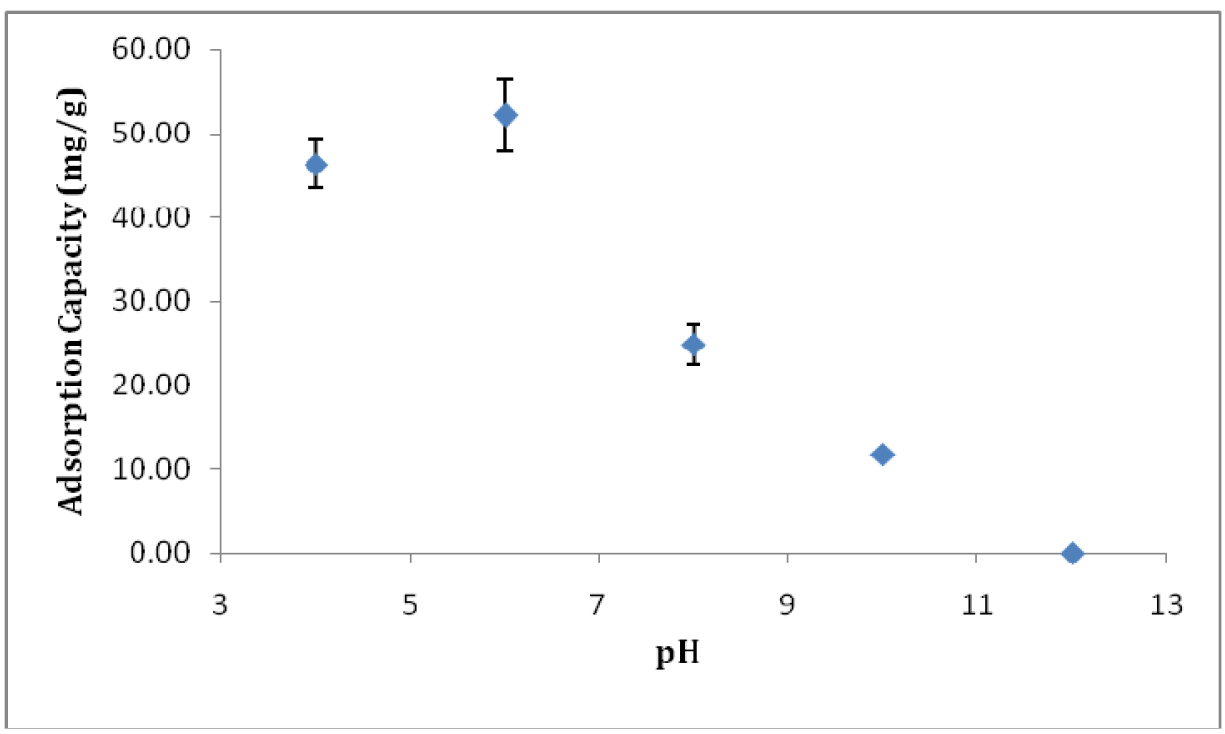

Figure 4. Effect of $\mathrm{pH}$ on the static adsorption capacity of PVA/PMA (80/20) membranes for lysozyme solutions $(0.2 \mathrm{mg} / \mathrm{mL})$.

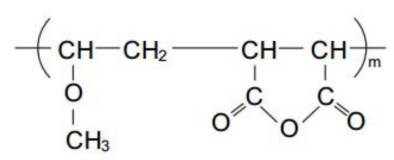

Poly(MVE/MA) (PMA)

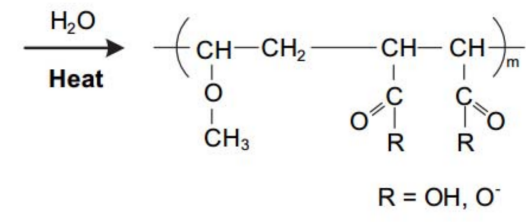

Incorporated spinning dopes with PVA $\overrightarrow{\text { Electrospinning }}$

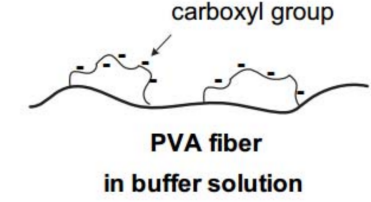

in buffer solution

Figure 5. Scheme of negative surface charges of PVA/PMA nanofibers. The $\mathrm{pH}=4$ is necessary to produce the hydrolysis. (Reprinted from ref. [15] with the permission of Elsevier). 


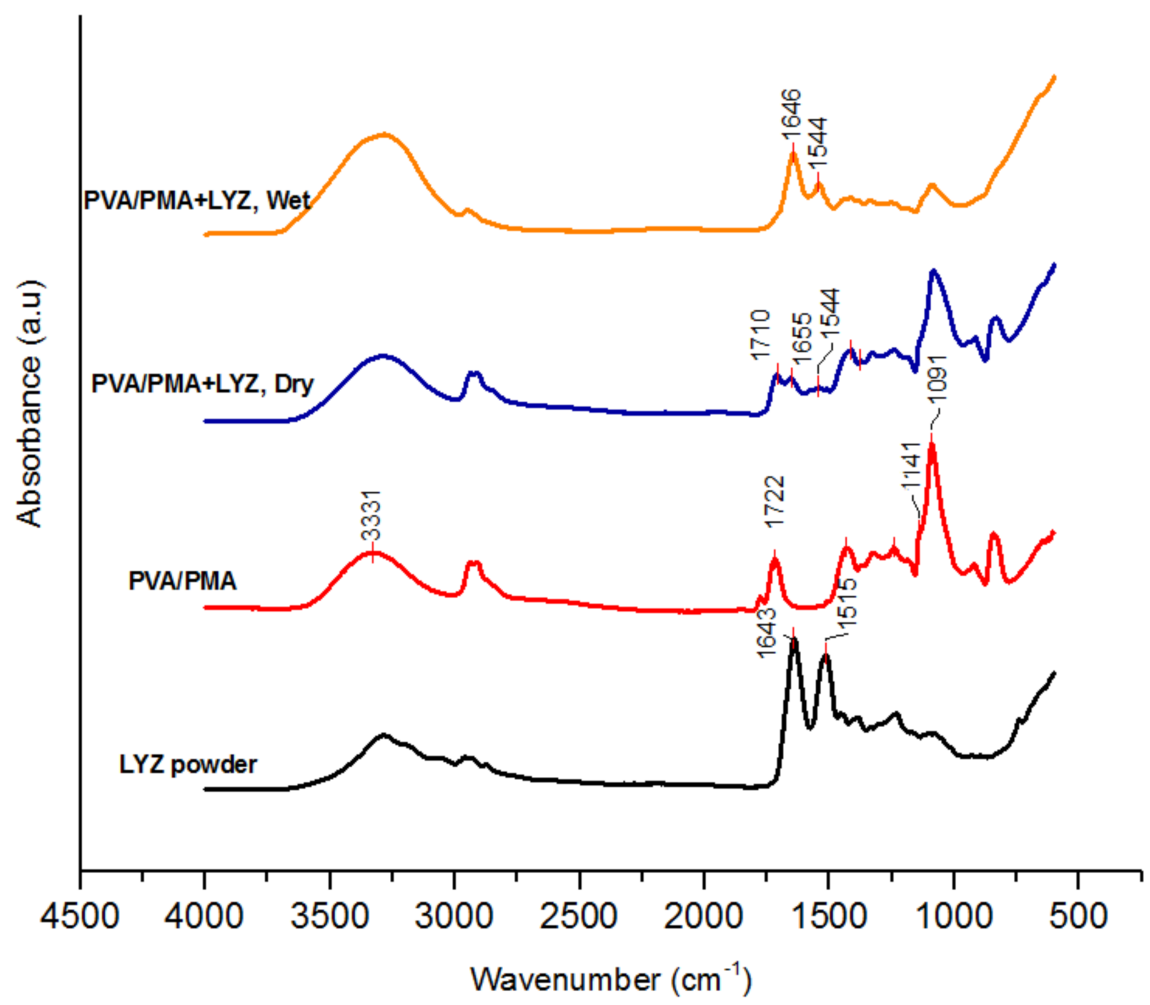

Figure 6. FTIR spectra of PVA/PMA (80/20) membrane before and after lysozyme adsorption.

\subsubsection{Effect of PMA Content}

The PMA content can considerably influence the protein adsorption, as it affects the number of carboxyl groups on the nanofiber surface. Table 2 shows the static lysozyme adsorption of PVA/PMA membranes at different PMA contents. Increasing the PMA from 10 to 20\% raised the adsorption capacity from $44.75 \pm 2.53$ to $80.07 \pm 3.71 \mathrm{mg} / \mathrm{g}$ by ca. $79 \%$. This addition also decreased the equilibrium time from 6 to about $4 \mathrm{~h}$. Such adsorption increase can be explained by the fact that at a higher amount of PMA, more adsorbent carboxylic groups are available on the membrane surface. Once in contact with the buffer solution, these carboxylic groups are ionized into carboxylate groups, resulting in a faster and higher capture of positively-charged proteins. The addition of 30\% PMA did not significantly increase the adsorption capacity due to the larger fiber diameter (Figure 2) and thus the smaller specific surface area of that membrane. As a high adsorption capacity was observed for the $80 / 20$ fiber, this sample was used for subsequent characterization tests.

FTIR was conducted on the membranes to confirm the increasing amount of PMA in the nanofibers. Figure 7 displays the FTIR spectra of the samples for different amounts of PMA. The absorbance peak at $1720 \mathrm{~cm}^{-1}$ is attributed to the carboxylic group of PMA. Also, the absorption peak at $1142 \mathrm{~cm}^{-1}$ related to C-O-C stretching is for crosslinking between PMA and PVA during heat treatment. The crosslinks are formed through an esterification reaction between maleic anhydride groups of PMA and the hydroxyl groups of PVA [12,15]. Table 3 shows the intensity ratios of the functional groups. The $\mathrm{C}-\mathrm{O}-\mathrm{C}$ (stretching)/C-O(stretching) ratio decreased and $\mathrm{C}=\mathrm{O}$ (stretching)/C-O(stretching) ratio increased with the PMA content, indicating more available carboxylic groups (-COOH) on the 80/20 or 70/30 nanofiber surface for lysozyme capture. 
Table 2. Static adsorption performance of PVA/PMA nanofiber membranes for different PMA contents (LYZ Conc.: $0.2 \mathrm{mg} / \mathrm{mL}$ ).

\begin{tabular}{ccc}
\hline PVA/PMA & $\mathrm{C}$ & $\mathbf{Q}_{\mathbf{e}}$ \\
\hline $\boldsymbol{w} / \boldsymbol{w}(\mathbf{\%})$ & $\mathbf{( m g / m L )}$ & $\mathbf{( m g / g )}$ \\
\hline $70: 30$ & 0.22 & $81.94 \pm 2.09$ \\
$80: 20$ & 0.21 & $80.07 \pm 3.71$ \\
$90: 10$ & 0.21 & $44.75 \pm 2.53$ \\
\hline
\end{tabular}

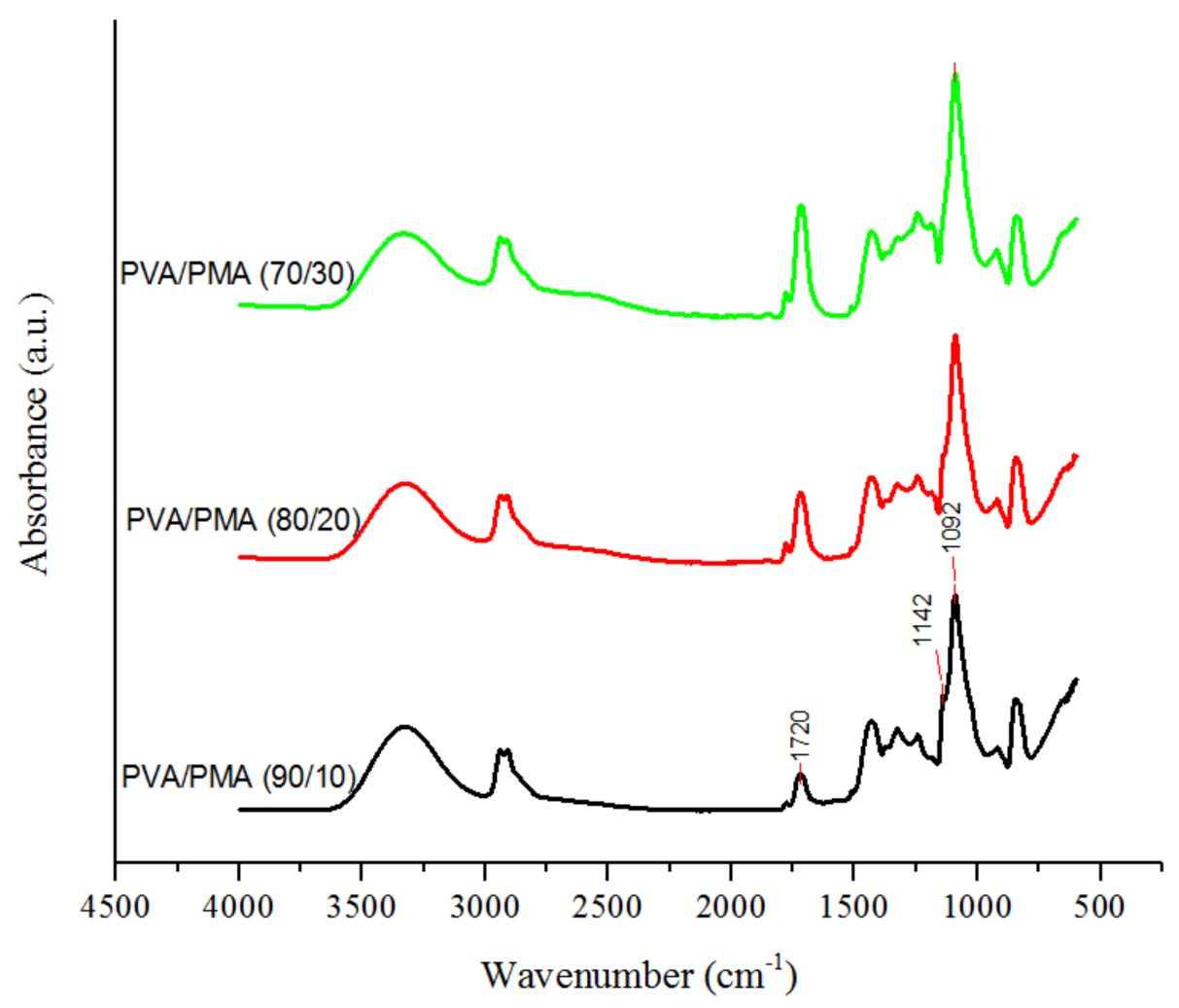

Figure 7. FTIR spectra of thermally treated PVA/PMA nanofiber membranes for different PMA contents.

Table 3. Adsorption ratios of $\mathrm{C}=\mathrm{O} / \mathrm{C}-\mathrm{O}$ and $\mathrm{C}-\mathrm{O}-\mathrm{C} / \mathrm{C}-\mathrm{O}$ in PVA/PMA nanofibers at different PMA contents.

\begin{tabular}{ccc}
\hline PVA/PMA & C=O/C-O & C-O-C/C-O \\
\hline $90 / 10$ & 0.16 & 0.54 \\
$80 / 20$ & 0.29 & 0.46 \\
$70 / 30$ & 0.43 & 0.38 \\
\hline
\end{tabular}

\subsection{Membrane Reusability}

Membrane reusability is the use of existing membranes for multiple cycles before replacing them. Reusing membranes can increase the operational flexibility and reduce material and labor costs. To investigate this, the adsorbed membrane was first eluted with sodium hyroxide ( $1 \mathrm{M})$, and was then rinsed with DI water using a syringe pump. Table 4 reveals the lysozyme concentration of the PVA/PMA (80/20) membrane before and after sodium hydroxide elution. As it can be seen, the base removed most of the proteins from the membranes. Interestingly, the adsorption capacity of the membrane before and after the elution was almost the same, indicating the effectiveness of 
the recycling process. This can be explained by the fact that the base increased the $\mathrm{pH}$ around the membrane, weakening the electrostatic interaction between the charged nanofibers and the charged protein. When $\mathrm{pH}>\mathrm{IP}$, both the lysozyme and nanofibers are negatively charged and the repulsive force between them results in the complete removal of the protein from the membrane surface. Figure 8 displays the morphology of the nanofiber membranes before and after elution. As can be seen, the nanofibers were a little bit swollen after the elution, due to the water absorbed by the PVA. Nevertheless, the physical structure of the fibers remained stable after elution due to chemical crosslinks between the polymers during heat treatment. The obtained results would enhance the practical applications of PVA/PMA membranes for protein separation.

Table 4. Lysozyme concentrations before and after the $\mathrm{NaOH}$ elution of PVA/PMA (80/20) membranes in a dynamic adsorption test.

\begin{tabular}{ccc}
\hline Solution & LYZ & Adsorption \\
\hline Type & Conc. $(\mathbf{m g} / \mathbf{m L})$ & Capacity $(\mathbf{m g} / \mathbf{g})$ \\
\hline Pristine LYZ solution & 0.18 & 0.0 \\
Effluent-1st LYZ Adsorption & 0.03 & 55.1 \\
Effluent-Base Elution & 0.17 & 14.1 \\
Effluent-2nd LYZ Adsorption & 0.02 & 59.6 \\
\hline
\end{tabular}
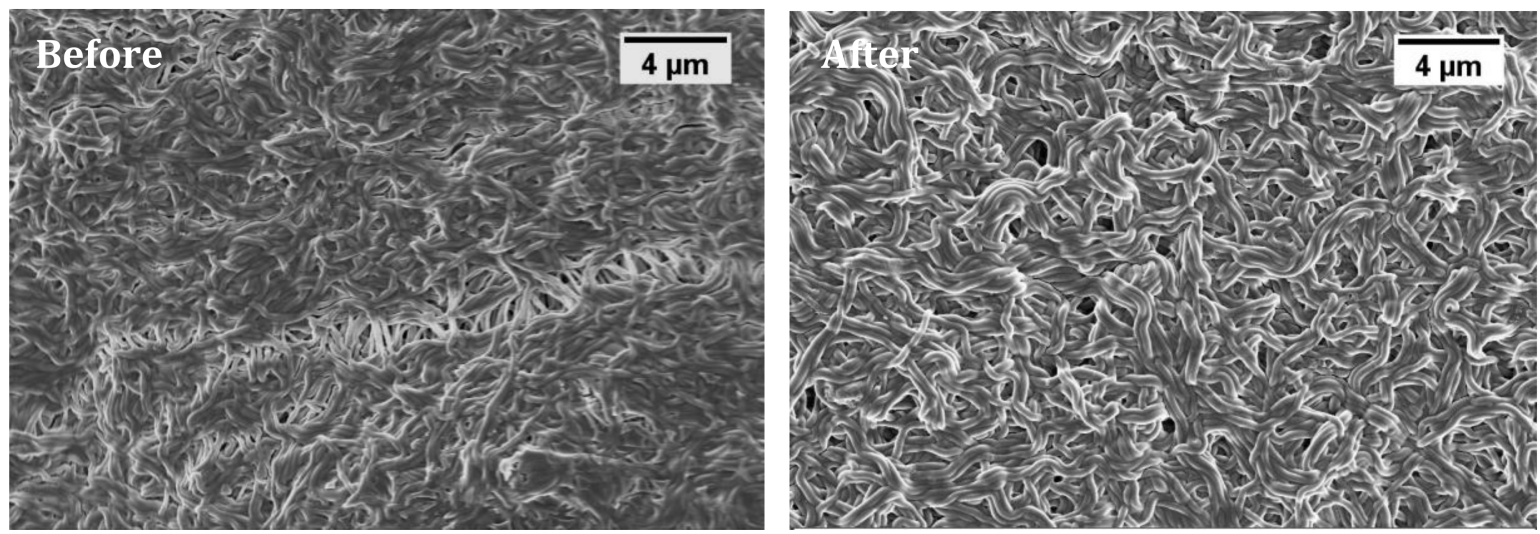

Figure 8. SEM images of PVA/PMA (80/20) nanofiber membrane adsorbed lysozyme before and after $\mathrm{NaOH}$ elution.

\subsection{Adsorption Selectivity}

Adsorption selectivity is one of the important features of polymer membranes. It indicates the ability of a membrane to capture a specific product from a mixture. The selectivity of PVA/PMA membranes for protein adsorption was examined by SDS-PAGE. LYZ (IP of 10.8) and BSA (IP of 4.8) were taken as positively- and negatively-charged model proteins, respectively. To examine the adsorption performance, LYZ solutions with various concentrations were also run with the protein mixture. As illustrated in Figure 9, it is clear that the band color of the lysozyme became lighter after they were adsorbed by the membranes. The band intensity was even lower than that of the $0.1 \mathrm{mg} / \mathrm{mL}$ LYZ solution, indicating that the PVA/PMA membrane mainly adsorbed the LYZ. At pH 6, the charges of the BSA and PVA/PMA nanofibers were both negative, while the charge of LYZ was positive. Thus, the nanofibers repelled the BSA and attracted the LYZ, leading to selective protein adsorption from a mixture. This result can be extended to other positive and negative proteins, increasing the versatility of PVA/PMA ENM for protein purification applications. 


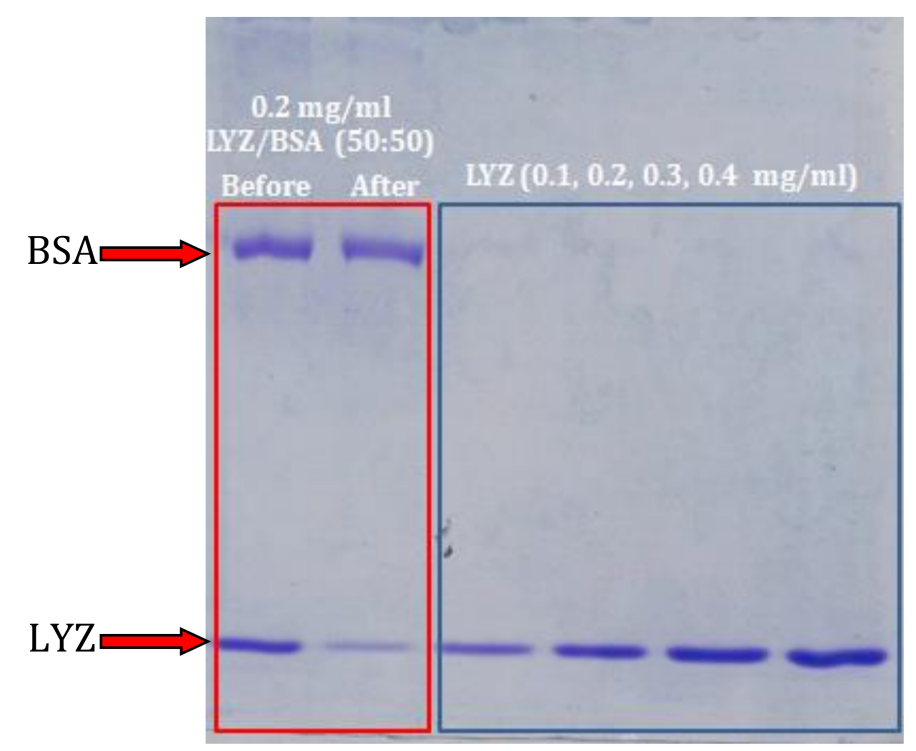

Figure 9. SDS-PAGE analysis for the purification of LYZ solutions and LYZ/BSA mixture (Buffer $\mathrm{pH}=6$ ).

\section{Conclusions}

In this study, PMA polymer was incorporated into electrospun PVA nanofibers to create composite membranes for protein adsorption. The effects of various parameters such as buffer $\mathrm{pH}$, PMA content, and protein concentration on the adsorption performance of the membranes were investigated. A high adsorption capacity of about $476 \mathrm{mg} / \mathrm{g}$ was obtained for the PVA/PMA $(80 / 20, w / w)$ membrane at $6 \mathrm{pH}$ buffer. This high capacity was due to the combined effects of the highly-specific surface area, highly porous structure, and abundant carboxyl groups of the nanofibers. By tailoring the $\mathrm{pH}$, the negatively-charged nanofibers selectively adsorbed positively-charged proteins from a protein mixture. Also, the results showed that the membranes can be regenerated/reused with no significant effect on the capture capacity. The PVA/PMA nanofibers exhibited great potential for the production of effective and low cost membranes for protein purification. Future work will focus on the utilization of these nanofibers for the separation of proteins in microfluidics analytical systems.

Author Contributions: M.N. designed and performed the experiments. M.M.F. supervised the study. J.C. contributed to electrospinning experiments. M.N. wrote the paper. All authors contributed to the analysis of the results.

Funding: The authors are grateful for the support provided by the USDA National Institute of Food and Agriculture, Hatch project NYS-3297402 and Hatch multistate project NC-1194 NYC-3297860. Any opinions, findings, conclusions, or recommendations expressed in this publication are those of the author(s) and do not necessarily reflect the view of the National Institute of Food and Agriculture (NIFA) or the United States Department of Agriculture (USDA). This work made use of the Cornell Center for Materials Research Shared Facilities which are supported through the NSF MRSEC program (DMR-1719875).

Acknowledgments: The authors also appreciate Alireza Abbaspourrad for letting us use SDS-PAGE equipment for this project. We also thank Ramin Pajoumshariati and Michael Selig for their contribution to SDS-PAGE experiments.

Conflicts of Interest: The authors declare no conflict of interest.

\section{References}

1. Bhakta, S.A.; Evans, E.; Benavidez, T.E.; Garcia, C.D. Protein adsorption onto nanomaterials for the development of biosensors and analytical devices: A review. Anal. Chim. Acta 2015, 872, 7-25. [CrossRef] [PubMed] 
2. Yi, S.; Dai, F.; Ma, Y.; Yan, T.; Si, Y.; Sun, G. Ultrafine Silk-Derived Nanofibrous Membranes Exhibiting Effective Lysozyme Adsorption. ACS Sustain. Chem. Eng. 2017, 5, 8777-8784. [CrossRef]

3. Li, G.; Li, T.; Li, Y.; An, L.; Li, W.; Zhang, Z. Preparation of pH-controllable nanofibrous membrane functionalized with lysine for selective adsorption of protein. Coll. Surf. A 2017, 531, 173-181. [CrossRef]

4. Wang, X.; Fu, Q.; Wang, X.; Si, Y.; Yu, J.; Wang, X.; Ding, B. In situ cross-linked and highly carboxylated poly(vinyl alcohol) nanofibrous membranes for efficient adsorption of proteins. J. Mater. Chem. B 2015, 3, 7281-7290. [CrossRef]

5. Fu, Q.; Wang, X.; Si, Y.; Liu, L.; Yu, J.; Ding, B. Scalable Fabrication of Electrospun Nanofibrous Membranes Functionalized with Citric Acid for High-Performance Protein Adsorption. ACS Appl. Mater. Interfaces 2016, 8, 11819-11829. [CrossRef] [PubMed]

6. Matlock-Colangelo, L.; Colangelo, N.W.; Fenzl, C.; Frey, M.; Baeumner, A.J. Passive mixing capabilities of micro-and nanofibres when used in microfluidic systems. Sensors 2016, 16, 1-18. [CrossRef] [PubMed]

7. Ma, Z.; Lan, Z.; Matsuura, T.; Ramakrishna, S. Electrospun polyethersulfone affinity membrane: Membrane preparation and performance evaluation. J. Chromatogr. B Anal. Technol. Biomed. Life Sci. 2009, 877, 3686-3694. [CrossRef] [PubMed]

8. Voicu, S.I.; Condruz, R.M.; Mitran, V.; Cimpean, A.; Miculescu, F.; Andronescu, C.; Miculescu, M.; Thakur, V.K. Sericin Covalent Immobilization onto Cellulose Acetate Membrane for Biomedical Applications. ACS Sustain. Chem. Eng. 2016, 4, 1765-1774. [CrossRef]

9. Chiu, H.-T.; Lin, J.-M.; Cheng, T.-H.; Chou, S.-Y.; Huang, C.-C. Direct purification of lysozyme from chicken egg white using weak acidic polyacrylonitrile nanofiber-based membranes. J. Appl. Polym. Sci. 2012, 125, 616-621. [CrossRef]

10. Zhang, H.; Wu, C.; Zhang, Y.; White, C.J.B.; Xue, Y.; Nie, H.; Zhu, L. Elaboration, characterization and study of a novel affinity membrane made from electrospun hybrid chitosan/nylon-6 nanofibers for papain purification. J. Mater. Sci. 2010, 45, 2296-2304. [CrossRef]

11. Schneiderman, S.; Zhang, L.; Fong, H.; Menkhaus, T.J. Surface-functionalized electrospun carbon nanofiber mats as an innovative type of protein adsorption/purification medium with high capacity and high throughput. J. Chromatogr. A 2011, 1218, 8989-8995. [CrossRef] [PubMed]

12. Xiao, M.; Chery, J.; Frey, M.W. Functionalization of Electrospun Poly(vinyl alcohol) (PVA) Nanofiber Membranes for Selective Chemical Capture. ACS Appl. Nano Mater. 2018, 1, 722-729. [CrossRef]

13. Matlock-Colangelo, L.; Cho, D.; Pitner, C.L.; Frey, M.W.; Baeumner, A.J. Functionalized electrospun nanofibers as bioseparators in microfluidic systems. Lab Chip 2012, 12, 1696-1701. [CrossRef] [PubMed]

14. Matlock-Colangelo, L.; Coon, B.; Pitner, C.L.; Frey, M.W.; Baeumner, A.J. Functionalized electrospun poly(vinyl alcohol) nanofibers for on-chip concentration of E. coli cells. Anal. Bioanal. Chem. 2016, 408, 1327-1334. [CrossRef] [PubMed]

15. Cho, D.; Matlock-Colangelo, L.; Xiang, C.; Asiello, P.J.; Baeumner, A.J.; Frey, M.W. Electrospun nanofibers for microfluidic analytical systems. Polymer 2011, 52, 3413-3421. [CrossRef]

16. Cho, D.; Lee, S.; Frey, M.W. Characterizing zeta potential of functional nanofibers in a microfluidic device. J. Colloid Interface Sci. 2012, 372, 252-260. [CrossRef] [PubMed]

17. Kim, K.W.; Lee, K.H.; Khil, M.S.; Ho, Y.S.; Kim, H.Y. The effect of molecular weight and the linear velocity of drum surface on the properties of electrospun poly(ethylene terephthalate) nonwovens. Fibers Polym. 2004, 5, 122-127. [CrossRef]

18. Akar, E.; Altinişik, A.; Seki, Y. Preparation of $\mathrm{pH}$ - and ionic-strength responsive biodegradable fumaric acid crosslinked carboxymethyl cellulose. Carbohydr. Polym. 2012, 90, 1634-1641. [CrossRef] [PubMed]

19. Xu, J.; Liu, W.; Yu, Y.; Du, J.; Li, N.; Xu, L. Synthesis of mono-dispersed mesoporous SBA-1 nanoparticles with tunable pore size and their application in lysozyme immobilization. RSC Adv. 2014, 4, 37470-37478. [CrossRef]

(C) 2018 by the authors. Licensee MDPI, Basel, Switzerland. This article is an open access article distributed under the terms and conditions of the Creative Commons Attribution (CC BY) license (http:/ / creativecommons.org/licenses/by/4.0/). 